\title{
Multiple Regression Analysis of Unconfined Compression Strength of Mine Tailings Matrices
}

\author{
Ali A. Mahmood ${ }^{1, *}$, and Maria Elektorowicz ${ }^{2}$ \\ ${ }^{1}$ Department of Civil Engineering, University College of Technology Sarawak, 868 Persiaran \\ Brooke, 96000 Sibu, Sarawak, Malaysia \\ ${ }^{2}$ Department of Building Civil and Environmental Engineering, Concordia University, Montreal, \\ Quebec H3G 1M8, Canada
}

\begin{abstract}
As part of a novel approach of sustainable development of mine tailings, experimental and numerical analysis is carried out on newly formulated tailings matrices. Several physical characteristic tests are carried out including the unconfined compression strength test to ascertain the integrity of these matrices when subjected to loading. The current paper attempts a multiple regression analysis of the unconfined compressive strength test results of these matrices to investigate the most pertinent factors affecting their strength. Results of this analysis showed that the suggested equation is reasonably applicable to the range of binder combinations used.
\end{abstract}

\section{Introduction}

Mine tailings are the waste materials resulting from the mining industry; they typically contain all other hazardous materials except the extracted material, left out from the processing of the ore. Mine tailings are usually disposed of in large impoundments surrounded by dams constructed not far away from the tailings mine. However, this classical method of disposal was the reason behind several severe tailings dam failures [1, $2,3]$. Hence, to lessen the harmful effects from the storage and failure of tailings dams and to attempt to economically benefit from these tailings in a sustainable manner, a new approach of managing these tailings was deployed and tested by several researchers. Researchers such as Demers and Haile [4], Zou and Sahito [5], Celik et al. [6] Roy at al. [7], Swami et al. [8], Onuaguluchi and Eren [9], Das et al. [10], Ugama et al. [11] and Sabat et al. [12] attempted to investigate the applicability of using tailings as substitutes to traditional building materials. While others like Belem and Benzaazoua [13], Fall et al. [14], Fall et al. [15], Benzaazoua et al. [16], Ercikdi et al. [17], Fall and Pokharel [18], Ercikdi et al. [19], Helinski et al. [20] and Helinski et al. [21] investigated the use of different mine tailings in the most traditional manner by using them as cemented paste backfill. The tailings, in many of these studies, have been mixed with cement to solidify and increase their effectiveness. However, cement is relatively expensive and hence the

\footnotetext{
* Corresponding author: ali.mahmood@ucts.edu.my
} 
need to add pozzolanic materials such as fly ash and slag to the tailings product to reduce cost and utilize the final product in a sustainable manner.

Recently there has been a new development in the additives sector with the advent of Calsifrit ${ }^{\mathrm{TM}}$. Calsifrit ${ }^{\mathrm{TM}}$ is a special cement that was developed by a Quebec Based company by the name of NovaFrit International [22]. It is a totally amorphous material, which is a matrix of calcium and sodium fluoro-aluminosilicate. It is a homogenous solid substance possessing high reactivity potential that shows cementitious properties when finely ground. No previous research study had been involved with testing the compression strength of mine tailings mixed with Calsifrit. Therefore, a comprehensive experimental and numerical research program was devised to formulate new tailings matrices and assess their suitability as road base materials in cold regions [23]. As part of this research program, this is an attempt to investigate computationally, using multiple regression analysis, the effect Portland cement, slag, fly ash and Calsifrit have on the unconfined compressive strength of these mine tailings matrices.

\section{Preparation of cylindrical specimens}

Cylindrical specimens of tailings matrices measuring (44 diameter x 74 height) $\mathrm{mm}$ were molded for the purpose of testing in accordance with ASTM D 4842 [24]. The binders used were the following: cement, Calsifrit, fly ash and slag. These cylindrical specimens were, subsequently, cured in the moisture chamber for 28 days in the case of wetting and drying, and for 43 days for the freezing and thawing testing. Unconfined compression tests were conducted on these mine tailings matrices after subjecting them to 12 cycles of drying at 60 ${ }^{\circ} \mathrm{C}$ and wetting by being submerged in room temperature distilled water. The freezing/thawing samples were compressed after 12 cycles of freezing at $-20{ }^{\circ} \mathrm{C}$ in a freezing cabinet and thawing in distilled water at room temperature $\left(22{ }^{\circ} \mathrm{C}\right)$. When performing the unconfined compression tests, speed of descent of the platen was kept constant at $70 \mathrm{~mm} / \mathrm{min}$. Cylindrical specimens of the tailings matrices were subjected to wetting/drying and freezing/thawing weathering resistance tests as further explained in Mahmood [23].

\section{The predictive equation}

In the modeling of engineered systems a recurrent problem may arise that where the dependent variable or variables (Y) are found to depend on a combination of independent variables $\left(\mathrm{x}_{1}, \mathrm{x}_{2}, \ldots . ., \mathrm{x}_{\mathrm{i}}\right)$ without the availability of a known physical mechanism describing this dependence. According to conventional statistical analysis such dependence can be best described using the method of multiple regression analysis. Such analysis can be based on fitting linear or polynomial equations, as described by Rumsey [25].

Multiple regression models can be used, both, to generate predictions based on previously unseen data and to explain observational relationships. In multiple regression the general form of the model is the following:

$$
Y=\beta_{o}+\beta_{1} X_{1}+\beta_{2} X_{2}+\ldots+\beta_{k} X_{k}+\varepsilon
$$

where $\beta_{\mathrm{o}}$ is the $\mathrm{Y}$ - intercept, $\beta_{\mathrm{i}}$ (where $\mathrm{i}=1$ to $\mathrm{k}$ ) represents the true slope of the regression surface in the $\mathrm{X}_{\mathrm{i}}$ direction, and $\varepsilon$ is the error term. The regression equation can be solved using the method of least squares, which generates the estimates for each of the beta $(\beta)$ coefficients. These estimates are represented by $b_{i}$. 
The UCS data for the wetting/drying and freezing/thawing experiments were fitted using design expert ${ }^{\circledR}$, which is a commercial software program used for the design of these experiments. Multiple regression analysis was used to fit the data together with the objective of finding a relevant predictive equation that fits the binders used with the UCS results.

Table 1 shows the data being fitted into this proposed model. Binder combinations were used to represent the factors of regression and the UCS was used as the response. Percentages of fly ash/binder, slag/binder, Calsifrit/binder, cement/binder, binder/tailings and type of weathering were used as the factors in developing this model. However, only the factors indicating the percentages of Calsifrit/binder, slag/binder and binder/tailings were found to be statistically relevant. As for the other 3 independent variables, since their effect was found to be statistically weak on the response variable (UCS), it was thought better not to include them in this model to avoid overfitting and to get a general view of the response. In the future, more models should be attempted using the same independent variables, to further ascertain this.

Table 1. The data used in the regression model

\begin{tabular}{|c|c|c|c|c|c|c|c|}
\hline $\begin{array}{c}\text { Run } \\
\text { No. }\end{array}$ & $\begin{array}{c}\text { Calsifrit/ } \\
\text { binder } \\
\text { ratio (\%) }\end{array}$ & $\begin{array}{c}\text { Fly } \\
\text { ash/binder } \\
\text { ratio (\%) }\end{array}$ & $\begin{array}{c}\text { Slag/ } \\
\text { Binder } \\
\text { ratio } \\
\mathbf{( \% )}\end{array}$ & $\begin{array}{c}\text { Cement/ } \\
\text { Binder } \\
\text { ratio (\%) }\end{array}$ & $\begin{array}{c}\text { Binder/ } \\
\text { Tailings } \\
\text { ratio } \\
\mathbf{( \% )}\end{array}$ & $\begin{array}{c}\text { Weathering( } \\
\text { 1: wetting/ } \\
\text { drying, 2: } \\
\text { freezing/ } \\
\text { thawing) }\end{array}$ & $\begin{array}{c}\text { UCS } \\
\text { (N/ } \\
\text { mm }\end{array}$ \\
\hline 1 & 0.00 & 0.00 & 0.00 & 100.00 & 50.00 & 1 & 24.43 \\
\hline 2 & 10.00 & 0.00 & 0.00 & 90.00 & 50.00 & 1 & 25.65 \\
\hline 3 & 25.00 & 0.00 & 0.00 & 75.00 & 50.00 & 1 & 25.24 \\
\hline 4 & 0.00 & 25.00 & 0.00 & 75.00 & 50.00 & 1 & 22.97 \\
\hline 5 & 10.00 & 15.00 & 0.00 & 75.00 & 50.00 & 1 & 26.22 \\
\hline 6 & 20.00 & 5.00 & 0.00 & 75.00 & 50.00 & 1 & 25.83 \\
\hline 7 & 0.00 & 0.00 & 25.00 & 75.00 & 50.00 & 1 & 28.62 \\
\hline 8 & 10.00 & 0.00 & 15.00 & 75.00 & 50.00 & 1 & 27.9 \\
\hline 9 & 20.00 & 0.00 & 5.00 & 75.00 & 50.00 & 1 & 29.47 \\
\hline 10 & 0.00 & 0.00 & 0.00 & 100.00 & 37.50 & 1 & 13.5 \\
\hline 11 & 10.00 & 0.00 & 0.00 & 90.00 & 37.50 & 1 & 16.41 \\
\hline 12 & 25.00 & 0.00 & 0.00 & 75.00 & 37.50 & 1 & 19.42 \\
\hline 13 & 0.00 & 25.00 & 0.00 & 75.00 & 37.50 & 1 & 16.91 \\
\hline 14 & 10.00 & 15.00 & 0.00 & 75.00 & 37.50 & 1 & 19.3 \\
\hline 15 & 20.00 & 5.00 & 0.00 & 75.00 & 37.50 & 1 & 21.79 \\
\hline 16 & 0.00 & 0.00 & 25.00 & 75.00 & 37.50 & 1 & 19.79 \\
\hline 17 & 10.00 & 0.00 & 15.00 & 75.00 & 37.50 & 1 & 20.09 \\
\hline 18 & 20.00 & 0.00 & 5.00 & 75.00 & 37.50 & 1 & 17.5 \\
\hline 19 & 0.00 & 0.00 & 0.00 & 100.00 & 50.00 & 2 & 23.51 \\
\hline 20 & 10.00 & 0.00 & 0.00 & 90.00 & 50.00 & 2 & 26.31 \\
\hline 21 & 25.00 & 0.00 & 0.00 & 75.00 & 50.00 & 2 & 27.1 \\
\hline 22 & 20.00 & 5.00 & 0.00 & 75.00 & 50.00 & 2 & 28.00 \\
\hline
\end{tabular}




\begin{tabular}{|c|c|c|c|c|c|c|c|}
\hline 23 & 0.00 & 0.00 & 25.00 & 75.00 & 50.00 & 2 & 25.7 \\
\hline 24 & 10.00 & 0.00 & 15.00 & 75.00 & 50.00 & 2 & 27.83 \\
\hline 25 & 20.00 & 0.00 & 5.00 & 75.00 & 50.00 & 2 & 24.88 \\
\hline 26 & 0.00 & 0.00 & 0.00 & 100.00 & 37.50 & 2 & 16.57 \\
\hline 27 & 10.00 & 0.00 & 0.00 & 90.00 & 37.50 & 2 & 20.94 \\
\hline 28 & 25.00 & 0.00 & 0.00 & 75.00 & 37.50 & 2 & 23.33 \\
\hline 29 & 0.00 & 25.00 & 0.00 & 75.00 & 37.50 & 2 & 17.78 \\
\hline 30 & 10.00 & 15.00 & 0.00 & 75.00 & 37.50 & 2 & 16.71 \\
\hline 31 & 20.00 & 5.00 & 0.00 & 75.00 & 37.50 & 2 & 16.65 \\
\hline 32 & 0.00 & 0.00 & 25.00 & 75.00 & 37.50 & 2 & 16.35 \\
\hline 33 & 10.00 & 0.00 & 15.00 & 75.00 & 37.50 & 2 & 16.74 \\
\hline 34 & 20.00 & 0.00 & 5.00 & 75.00 & 37.50 & 2 & 20.11 \\
\hline
\end{tabular}

The final equation, based on this analysis, describing the dependency of UCS on binder combinations was found to be the following:

$$
U C S=-6.856+0.14 A+0.092 C+0.6198 E
$$

where A: Calsifrit/binder ratio (\%), C: slag/binder ratio (\%), E: binder/tailings ratio (\%).

It was found during the analysis that the effect of cement could not be associated directly with UCS. Its effect was evident in biner/tailings ratio (E), as this ratio includes cement as the main binder constituent. Table 2 shows the Analysis of Variance (ANOVA) calculated for this model. The $\mathrm{P}$ values were found to be much less than the required 0.05 indicating that significance level has been reached.

Table 2. The Analysis of Variance of the regression model

\begin{tabular}{|l|c|c|c|c|c|}
\hline The Source & $\begin{array}{c}\text { Sum of } \\
\text { Squares } \\
\text { (SS) }\end{array}$ & $\begin{array}{c}\text { df (degrees } \\
\text { of freedom) }\end{array}$ & $\begin{array}{c}\text { Mean } \\
\text { Square }\end{array}$ & F - value & P - value \\
\hline Model & 580.11 & 3 & 193.37 & 58.93 & $<0.0001$ \\
\hline A-A & 47.27 & 1 & 47.27 & 14.41 & 0.0007 \\
\hline C-C & 18.76 & 1 & 18.76 & 5.72 & 0.0233 \\
\hline E-E & 506.2 & 1 & 506.2 & 154.25 & $<0.0001$ \\
\hline Residual & 98.45 & 30 & 3.28 & & \\
\hline
\end{tabular}

Equation (2) is specifically applicable to the range of binder combinations and the two types of weathering used. If different binder combinations and ratios are required, beyond the range used here, it is best to base a new equation on the new binder combinations. This is advised to retain a high numerical accuracy and closer proximity to experimental results.

The mathematical difference between the observed $\left(\mathrm{y}_{\mathrm{i}}\right)$ and model predicted $\left(\mathrm{y}_{\mathrm{i}}{ }_{\mathrm{i}}\right)$ values of the dependent variable, for a certain given set of independent variables, specifically $\mathrm{y}_{\mathrm{i}^{-}}$ $\mathrm{y}_{\mathrm{i}}{ }_{\mathrm{i}}$, is known as the prediction error or residual. In order for any mathematical model to be valid, four assumptions regarding the model residuals must be met [26]:

- Residuals are normally distributed

- Residuals have a mean of zero

- Residuals have a constant variance

- Residuals are independent 
One key assumption that must be fulfilled in order for any model to be valid is that the residuals are normally distributed. In order for this assumption to hold true a plot of the residuals must look like a random sample from a normal bell-shaped distribution. Histograms and normal scores plots are considered useful tools for detecting the normalcy of residuals. In the case of the latter, a straight line plot should be expected. Another assumption made in the development of the statistical model is that all data points are collected with equal precision. In order for this assumption to hold true, a plot of the model residuals against model predictions should be free of obvious trends. The third assumption concerning these residuals relates to their independence with respect to time and the values of the model variables. For this assumption to be true, plots of residuals in time order, as well as plots of residuals against the values of the dependent and independent variables, must be free of any obvious trend. The fourth and final assumption suggests that a good model fit will have residuals that are scattered around a mean of zero [26].

The first condition to meet is that the residuals must have a normal distribution with a mean zero. The software Design-Expert C [27] is used to draw the statistical figures shown below. Figure 1 below shows how well the residuals match a normal distribution. The residuals fall on a straight line, which means that the normality condition was met.

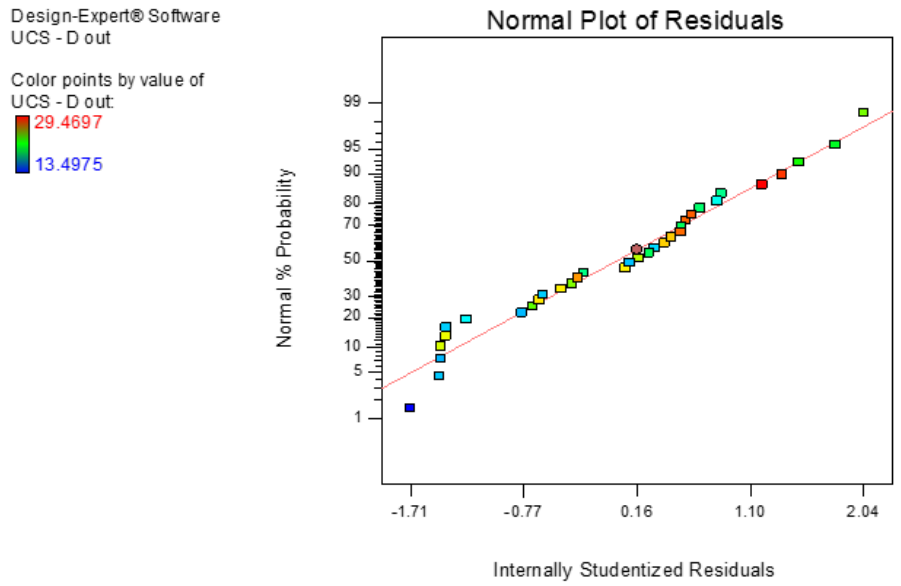

Fig. 1. Normal probability plot of model residuals

Fig. 2 shows a plot of the model residuals versus predicted UCS values. The horizontal line across that plot is at zero as a marker. Residuals were centered around zero in a manner that has no predictable pattern, with the same amount of variability around the horizontal line that crosses at zero from left to right. This plot shows more residuals scattered around zero, where the middle lump would be on a standard normal distribution plot, and fewer and fewer residuals as we move away from zero. Due to all of this, this plot confirms the normal distribution criteria. The residuals average out at the zero line, which indicates that the mean of zero condition holds for these residuals.

Fig. 2 shows no change in the amount of spread in the residuals around the horizontal zero line as we move from left to right or vice versa. This clearly indicates that condition three; the residuals have constant variance, has been met. Fig. 3 that shows the residuals plotted by observation order indicates no discernible pattern. This shows that condition four; the residuals are independent, has been met. 


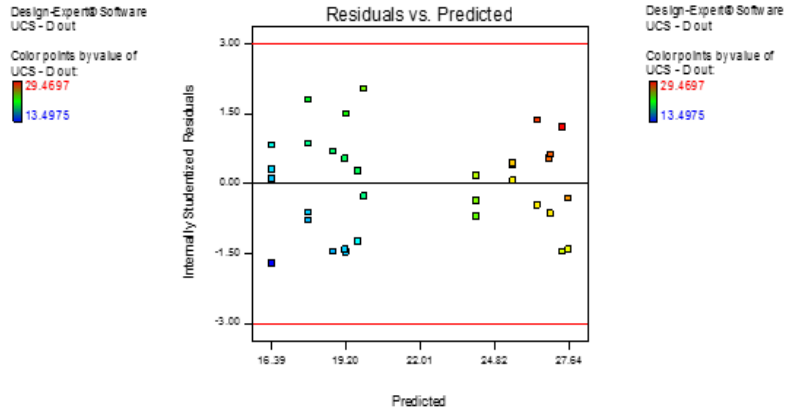

Fig. 2. The residual vs. predicted UCS values

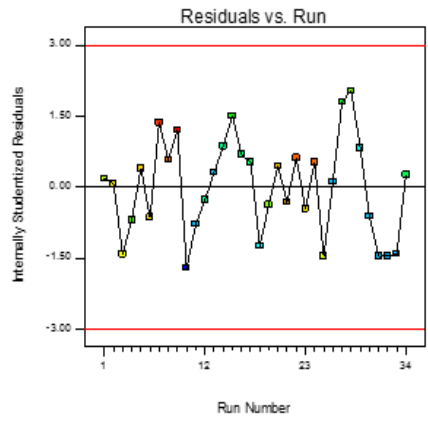

Fig. 3. The residuals plotted by observation order

Plots of the model residuals against each of the independent variables were found to be free of trends as can be seen in Fig. 4 to 9 . They also seem to cluster symmetrically around the middle line. This shows that the suggested model is correct and the assumption of linearity is accurate.

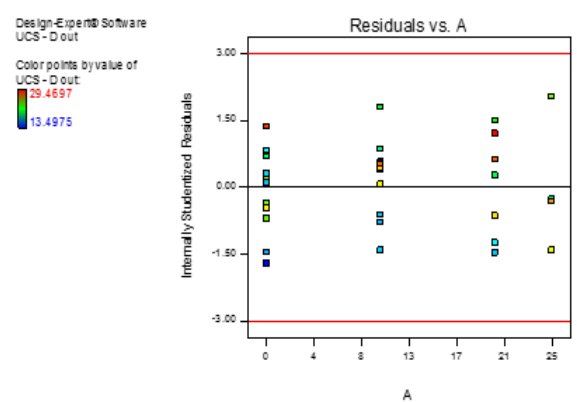

Fig. 4. The residuals vs. Calsifrit/binder ratio ash/binder

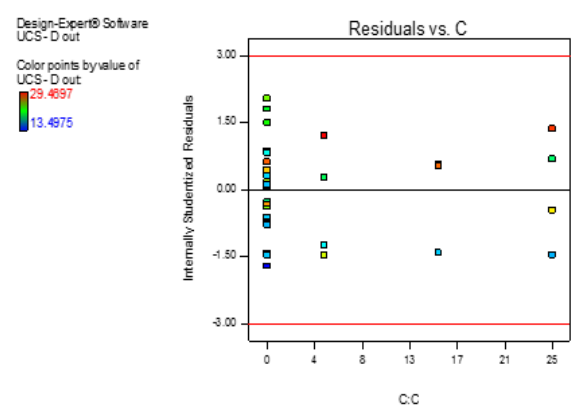

Fig. 6. The residuals vs. slag/binder ratio cement/binder
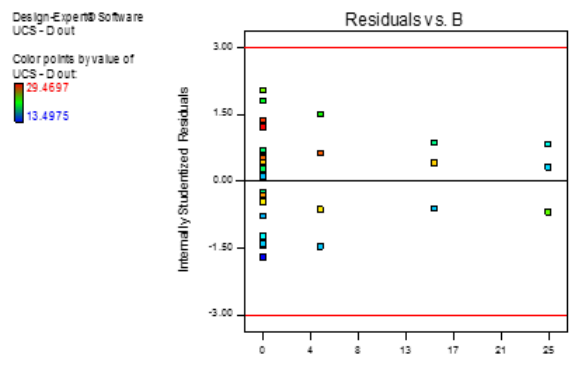

B:B

Fig. 5. The residuals vs. fly ratio
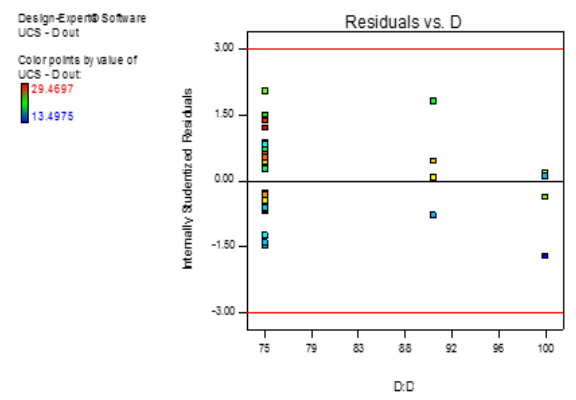

Fig. 7. The residuals vs. ratio 


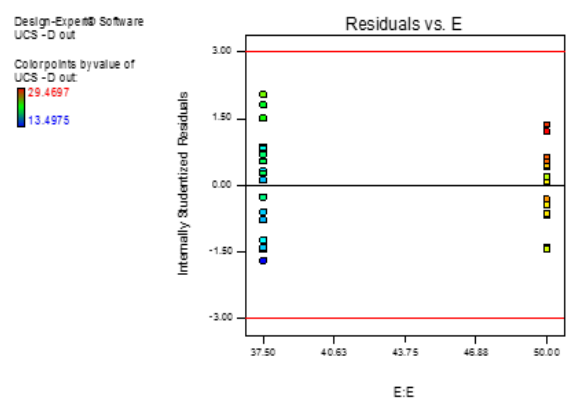

Fig. 8. The residuals vs. binder/tailings ratio
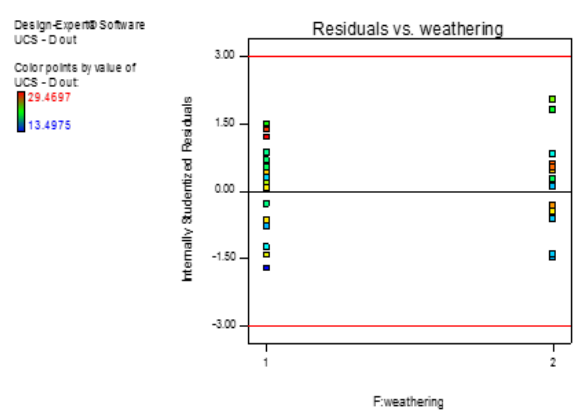

Fig. 9. The residuals vs. weathering type; 1 for wetting/dryin and 2 for freezing/thawing

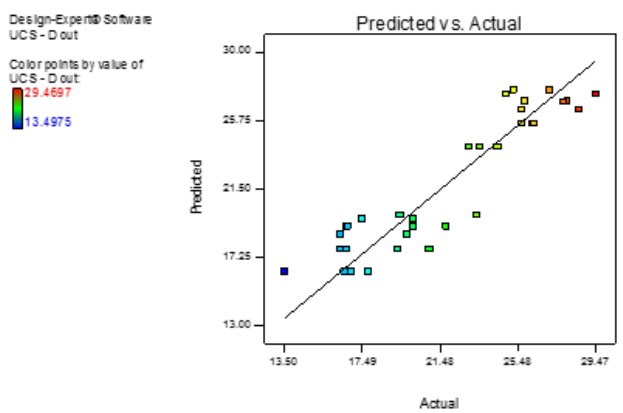

Fig. 10. The predicted vs. actual UCS values

Fig. 10 shows a good correlation between predicted versus actual values. However, more tests need to be conducted using the same independent variables suggested here to fine tune the model and get a more accurate representation of these independent variables. Calsifrit was shown to be a relevant factor in the unconfined compression equation. The latter finding was further confirmed by experimental results [23].

\section{Conclusion}

The above indicates that the multiple regression model suggested here is reasonable and can be used for the prediction of the unconfined compressive strength of mine tailings matrices, based on the variables used. Calsifrit, was shown to be a relevant factor in the unconfined compression equation. The proposed Equation applicable to the range of binder combinations and the 2 types of weathering used. If different binder combinations are required, beyond the range used above, it is best to base a new equation on the new binder combinations. This is done in order to retain a high numerical accuracy and closer proximity to experimental results. The proposed Equation needs to be validated with more experimental data using the same independent variables.

\section{References}

[1] A. B. Fourie and G. Papageorgiou. Defining an appropriate steady state line for Merriespruit gold tailings, Canadian Geotechnical J., 38(4), 695-706 (2001) 
[2] A. B. Fourie, G.E. Blight and G. Papageorgiou. Static liquefaction as a possible explanation for the Merriespruit tailings dam failure, Canadian Geotechnical J., 38(4), 707-719 (2001)

[3] World Information Service on Energy-Uranium Project, website information: http://www.wise-uranium.org/index.html, retrieved in (2012)

[4] B. Demers and G. Haile, Management of tailings stabilized by lime and cement at Canadian electrolytic zinc, Valleyfield, Quebec, Proceedings of Sudbury 2003 Mining and the Environment, Sudbury, Ontario (2003)

[5] D.H. Zou and W. Sahito, Suitability of mine tailings for shotcrete as a ground support, Canadian J. of Civil Engineering, 31(4), 632-636 (2004)

[6] O. Celik, I.Y. Elbeyli and S. Piskin, Utilization of gold tailings as an additive in Portland cement, Waste Management and Research, 24(3), 215-224 (2006)

[7] S. Roy, G.R. Adhikari and R.N. Gupta, Use of gold mill tailings in making bricks: A feasibility study, Waste Management and Research, 25(5), 475-482 (2007)

[8] R.K. Swami, N.K.S. Pundhir and S. Mathur. Kimberlite tailings a road construction material, J. of the Transportation Research Board, 2(1989), 131-134 (2007)

[9] O. Onuaguluchiand and Ö.Eren. Cement mixtures containing copper tailings as an additive: durability properties. Materials Research, 15(6), 1029-1036 (2012)

[10] S.K. Das, J. Ghosh, A.K. Mandal, N. Singh and S. Gupta, Iron ore tailing: A waste material used in ceramic tile compositions as alternative source of raw materials, Transactions of the Indian Ceramic Society. 71(1), 21-24 (2012)

[11]T.I. Ugama, S.P. Ejeh and D.Y. Amartey, Effect of tailings on the properties of concrete, IISTE, 6 (10), (2014)

[12] V. Sabat, M. Shaikh, M. Kanap, M. Chaudhari, S. Suryawanshi and K. Knadgouda, Use of iron ore tailings as a construction material, Int. J. of Conceptions on Mechanical and Civil Engineering, 3(2), (2015)

[13]T. Belem and M. Benzaazoua, An overview on the use of paste backfill technology as a ground support method in cut-and-fill mines, Proc. of the 5th Int. Symp. on Ground support in Mining and Underground Construction, Tayler and Francis, London, 637650 (2004)

[14] M. Fall, M. Benzaazoua and S. Ouellet. Experimental characterization of the influence of tailings fineness and density on the quality of cemented paste backfill. Minerals Engineering, 18(1), 41-44 (2005)

[15]M. Fall, M. Benzaazoua and E.G. Saa, Mix proportioning of underground cemented tailings backfill, Tunnelling and Underground Space Technology, 23(1), 80-90 (2008)

[16] M. Benzaazoua, B. Bussiere, I. Demers, M. Aubertin, E. Fried and A. Blier, Integrated mine tailings management by combining environmental desulphurization and cemented paste backfill: Application to mine Doyon, Quebec, Canada, Minerals Engineering, 21(4), 330-340 (2008)

[17]B. Ercikdi, A. Kesimal, F. Cihangir, H. Deveci and I. Alp, Cemented paste backfill of sulphide-rich tailings: importance of binder type and dosage, Cement and Concrete Composites, 31(4), 268-274 (2009)

[18]M. Fall and M. Pokharel, Coupled effects of sulphate and temperature on the strength development of cemented tailings backfills: Portland cement-paste backfill, Cement and Concrete Composites, 32(10), 819-828 (2010)

[19]B. Ercikdi, F. Cihangir, A. Kesimal, H. Deveci and I. Alp. Effect of natural pozzolans as mineral admixture on the performance of cemented-paste backfill of sulphide-rich tailings. Waste Management and Research, 28(5), 430-435 (2010) 
[20]M. Helinski, M. Fahey and A. Fourie. Coupled two-dimensional finite element modeling of mine backfilling with cemented tailings, Canadian Geotechnical J., 47(11), 1187-1200 (2010)

[21] M. Helinski, M. Fahey and A. Fourie, Behavior of cemented paste backfill in two mine stopes: measurements and modelling, J. of Geotechnical and Geo-environmental Eng., 137(2), 171-182 (2011)

[22] NovaFrit International, 1200 Garnier Street, Ville Ste-Catherine, Quebec, J0L 1E0 (2006)

[23]A.A. Mahmood, Experimental and computational assessment of tailings binder matrices for construction purposes in cold regions, $\mathrm{PhD}$ Thesis, Concordia University, Canada (2012)

[24] ASTM D 4842-90, Standard test method for determining the resistance of solid wastes to freezing and thawing, Annual Book of ASTM Standards, American Society for Testing and Materials, Philadelphia, (1996)

[25]D. Rumsey, Intermediate statistics for dummies, John Wiley and Sons, New Jersey, (2007)

[26] C.W. Baxter, D.W. Smith and S.J. Stanley, A comparison of artificial neural networks and multiple regression methods for the analysis of pilot scale data, J. of Environmental Engineering and Science, 3(S1), S45-S58 (2004)

[27] Stat-Ease. Stat-Ease, Inc. 2021 E. Hennepin Avenue, Suite 480 Minneapolis, MN 55413-2726, USA (2008). 